\title{
PRODUCTION OF PLANT PROTECTION AGENTS IN MEDIUM CONTAINING WASTE GLYCEROL BY STREPTOMYCES HYGROSCOPICUS: BIOPROCESS ANALYSIS
}

\author{
I. Mitrovića*, J. Grahovac ${ }^{\mathrm{a}}$, J. Dodića ${ }^{\mathrm{a}}$, A. Jokića ${ }^{\mathrm{a}}$ Z. RončEviĆ ${ }^{\mathrm{a}}$ and M. Grahovac ${ }^{\mathrm{b}}$ \\ ${ }^{\mathrm{a}}$ Faculty of Technology, University of Novi Sad, Novi Sad. Serbia \\ ${ }^{b}$ Faculty of Agriculture, University of Novi Sad, Novi Sad. Serbia
}

(Received: 18 December 2019; accepted: 11 May 2020)

\begin{abstract}
The surplus of waste glycerol, by-product of the biodiesel production process, is available at the global market. Some species of the genera Streptomyces have the ability to assimilate glycerol and convert it into valuable metabolic products. In the present study, the ability of Streptomyces hygroscopicus to assimilate waste glycerol and convert it into metabolic compounds with antifungal activity against four phytopathogenic fungi obtained from apple fruit samples expressing rot symptoms, was investigated. Production of antifungal metabolites by S. hygroscopicus was carried out in 31 stirred tank bioreactor through 7 days. Fermentation was carried out at $27^{\circ} \mathrm{C}$ with aeration rate of $1.5 \mathrm{vvm}$ and agitation rate of 100 r.p.m. The aim of this work was to analyse bioprocess parameters and to determine at which stage of bioprocess the production of antifungal metabolites occurs. Activity of the cultivation liquid on two isolates of Alternaria alternata and two isolates of Fusarium avenaceum were determined every $12 \mathrm{~h}$ using in vitro well diffusion method. It was found that the maximum production of antifungal metabolites occurred at 108 hour of cultivation. Formed inhibition zones have shown that the produced antifungal metabolites have high efficacy on tested phytopathogenic fungi (inhibition zone diameter higher than $35 \mathrm{~mm}$ for all test organisms).
\end{abstract}

Keywords: Streptomyces hygroscopicus, bioprocess, waste glycerol, postharvest apple disease, biocontrol

Biodiesel is an alternative to fossil fuels. However, during production of biodiesel and its by-products, waste glycerol is also produced (Roume et al., 2016). As the waste glycerol purification process is unprofitable, after biodiesel production it stays behind as waste. The production of biodiesel could generate $10 \%$ of waste glycerol, and an increase in biodiesel production would raise the need for finding efficient treatment or utilisation of waste glycerol (ONDul \& Dizge, 2014). However, some microorganisms have the ability to assimilate waste glycerol and convert it into value-added metabolic products (CHATZIFRAGKOU et al., 2011). Streptomycetes are known to have a great potential for the use of glycerol, and some scientists have shown that in addition to pure glycerol, this genus is able to grow and produce active metabolites in medium containing waste glycerol as well (ĆIRIĆ et al., 2012; DoDD et al., 2018).

Usage of microorganisms in biological control of plant pathogens is considered an alternative to chemical-based treatments, with minimal impact on the environment (JIANG et al., 2019). Certainly, the decreasing effectiveness of fungicides, as well as the risks of their use, indicates the need for more effective and safe control measures (MUTHUKUMAR et al., 2016; Sharma et al., 2016). However, production of biofungicide is an important step to its commercial use, but one of the biggest problems of production and application of biological products is their high price. Therefore, considerable interest has been shown in usage of agricultural wastes and by-products from food industry as cultivation medium, in order to

* To whom correspondence should be addressed.

Phone: +381 21485 3640; fax: +38121450 413; e-mail: tadi@uns.ac.rs

0139-3006 C 2020 The Author(s) 
reduce upstream costs (NUNES, 2012). Regarding this fact, waste glycerol seems to be a promising component in cultivation media used for production of active agents by Streptomyces spp.

In this paper, the ability of Streptomyces hygroscopicus to produce storage apple pathogen antagonist substances in medium with waste glycerol was examined. Production of antifungal metabolites by $S$. hygroscopicus was carried out in 31 stirred tank bioreactor at $27{ }^{\circ} \mathrm{C}$ through 7 days with aeration rate of $1.5 \mathrm{vvm}$ and agitation rate of 100 r.p.m. The aim of this work was to analyse bioprocess parameters and to determine at which stage of bioprocess the production of antifungal metabolites occurs. Activity of the cultivation liquid on two isolates of Alternaria alternata and two isolates of Fusarium avenaceum obtained from rotten apple fruit were determined every $12 \mathrm{~h}$ using in vitro well diffusion method.

\section{Materials and methods}

\subsection{Antagonistic microorganism}

In this study, soilborne Streptomyces hygroscopicus was used as antagonistic microorganism, isolated from soil sample in the territory of Novi Sad, Serbia and stored in the Microbial Culture Collection of the Faculty of Technology in Novi Sad, Serbia. This microorganism was deposited under GenBank Accession number KT026467.

The growing medium had the following composition $\left(\mathrm{g} \mathrm{l}^{-1}\right)$ : glucose (15.0), soybean meal (10.0), $\mathrm{CaCO}_{3},(3.0), \mathrm{NaCl},(3.0), \mathrm{MgSO}_{4},(0.5),\left(\mathrm{NH}_{4}\right)_{2} \mathrm{HPO}_{4},(0.5)$, and $\mathrm{K}_{2} \mathrm{HPO}_{4},(1.0)$. The $\mathrm{pH}$ of the medium was adjusted to $7.2 \pm 0.1$ (Consort C863, Turnhout, Belgium) prior to autoclaving.

\subsection{Fungal pathogens for bioassay}

Two Alternaria alternata isolates (KA10 and T1Jg3) and two Fusarium avenaceum isolates (KA12 and KA13) were used in the study as test microorganisms. The isolates were obtained from apple fruit expressing rot symptoms from Ultra Low Oxygen storages in Vojvodina Province, Serbia and kept as monosporial culture on Potato Dextrose Agar (PDA) slants at $4{ }^{\circ} \mathrm{C}$. The isolates were identified by conventional phytopathological and molecular methods (Polymerase Chain Reaction (PCR) using species-specific primers).

All isolates were initially grown on PDA plates for seven days. A small amount of mycelium of each isolate was added to flasks containing $50 \mathrm{ml}$ of Potato Dextrose Broth (PDB). The flasks were incubated for $48 \mathrm{~h}$ on a rotary shaker $\left(150\right.$ r.p.m.) at $25^{\circ} \mathrm{C}$. Before activity studies, the growth medium was filtered through double layer of sterile cheesecloth (grade 40).

\subsection{Bioreactor studies}

Production of bioagents effective against Alternaria and Fusarium phytopathogenic isolates were performed in a bioreactor (Biostat Aplus, Sartorius AG, Germany) with a total volume of 31 and a working volume of 21 with internal mixing using two parallel Rushton turbines and without internal baffles. Process parameters were controlled automatically. The ratio of vessel to stirrer diameter (Di/D) was 2.6. Production of antagonists to apple storage pathogens was performed for $168 \mathrm{~h}$ under aerobic conditions with aeration rate of $1.5 \mathrm{vvm}$ and agitation rate of 100 r.p.m. 
The medium used for the biosynthesis of antifungal metabolites contained waste glycerol enriched with $\left(\mathrm{NH}_{4}\right)_{2} \mathrm{SO}_{4}\left(0.25 \mathrm{~g} \mathrm{l}^{-1}\right)$ as nitrogen source. Since the waste glycerol used in this study contained $60 \%$ of glycerol, the medium for the biosynthesis of active bioagents was formulated to contain $20 \mathrm{~g} \mathrm{l}^{-1}$ of total glycerol.

Two litres of fermentation medium was inoculated at $10 \%(\mathrm{v} / \mathrm{v})$ by a preculture after 72 $\mathrm{h}$ growth on a rotary shaker (IKA KS 4000i Control Incubating Shaker) at 150 r.p.m.

\subsection{Analytical methods}

Cultivation liquid was tested every $12 \mathrm{~h}$ of cultivation. The sample of the cultivation medium was centrifuged at $10000 \mathrm{~g}$ (Eppendorf Centrifuge 5804th) for $10 \mathrm{~min}$ and the supernatant of the cultivation medium was used for further analysis.

Total nitrogen content was determined in the liquid phase of the cultivation medium using Kjeldahl method (EPA Manual). Standard method was used to determine phosphorus content (GALES et al., 1966).

The residual glycerol content was determined by HPLC measurement. Samples were filtered through $0.45 \mu \mathrm{m}$ nylon filter (Agilent Technologies, Germany) before analysis. The HPLC instrument was equipped with pump HPG-3200SD/RS, autosampler WPS-3000(T) SL (10-1l injection loop), column ZORBAX NH2 $(250 \mathrm{~mm} \times 4.6 \mathrm{~mm}, 5 \mu \mathrm{m})$, and detector Refracto- Max520. As eluent, 75\% (v/v) acetonitrile was used with flow rate of $1.2 \mathrm{ml} \mathrm{m^{-1 }}$ and elution time of $20 \mathrm{~min}$ at column temperature of $30^{\circ} \mathrm{C}$.

Samples $(10 \mathrm{ml})$ were centrifuged at $10000 \mathrm{~g}$ for $10 \mathrm{~min}$ at $20{ }^{\circ} \mathrm{C}$. The supernatants were discarded and the cell pellet was re-suspended in an equal volume of distilled water and re-centrifuged as above. The cell biomass was dried at $105{ }^{\circ} \mathrm{C}$ overnight and weighed. All determinations were performed in duplicate (MEANWELl \& SHAma, 2008).

\subsection{In vitro assay}

In vitro antagonistic activity assay was performed in $85 \mathrm{~mm}$ Petri dishes using wells technique (TADIJAN et al., 2016). In short, two layers of PDA medium were poured. The first layer consisted of $2 \%$ PDA medium. After solidification, the second layer composed of $1.2 \%$ PDA and filtered fungal culture liquid $(35 \%)$ was added. Three wells per plate with a diameter of $10 \mathrm{~mm}$ were made, two plates represented one treatment. For each treatment, $100 \mu \mathrm{l}$ of Streptomyces hygroscopicus supernatant was added to each well. After $72 \mathrm{~h}$ of incubation at $25^{\circ} \mathrm{C}$, diameter $(\mathrm{mm})$ of mycelia growth inhibition zone around the wells was measured.

\subsection{Data analysis}

Inhibition zone diameter data obtained by testing the supernatant of S. hygroscopicus through 7 days of cultivation on four test isolates were processed by factorial ANOVA using Software STATISTICA 13.

\section{Results and discussions}

\subsection{Time-course of substrate consumption and cell growth during cultivation}

In order to monitor the ongoing processes in the laboratory bioreactor, contents of the most important nutrients, i.e. sources of carbon, nitrogen, and phosphate, during the cultivation 
were measured. Also, changes in the biomass of the producer microorganism were monitored as dry weight of cells. The results are shown in Figure 1.
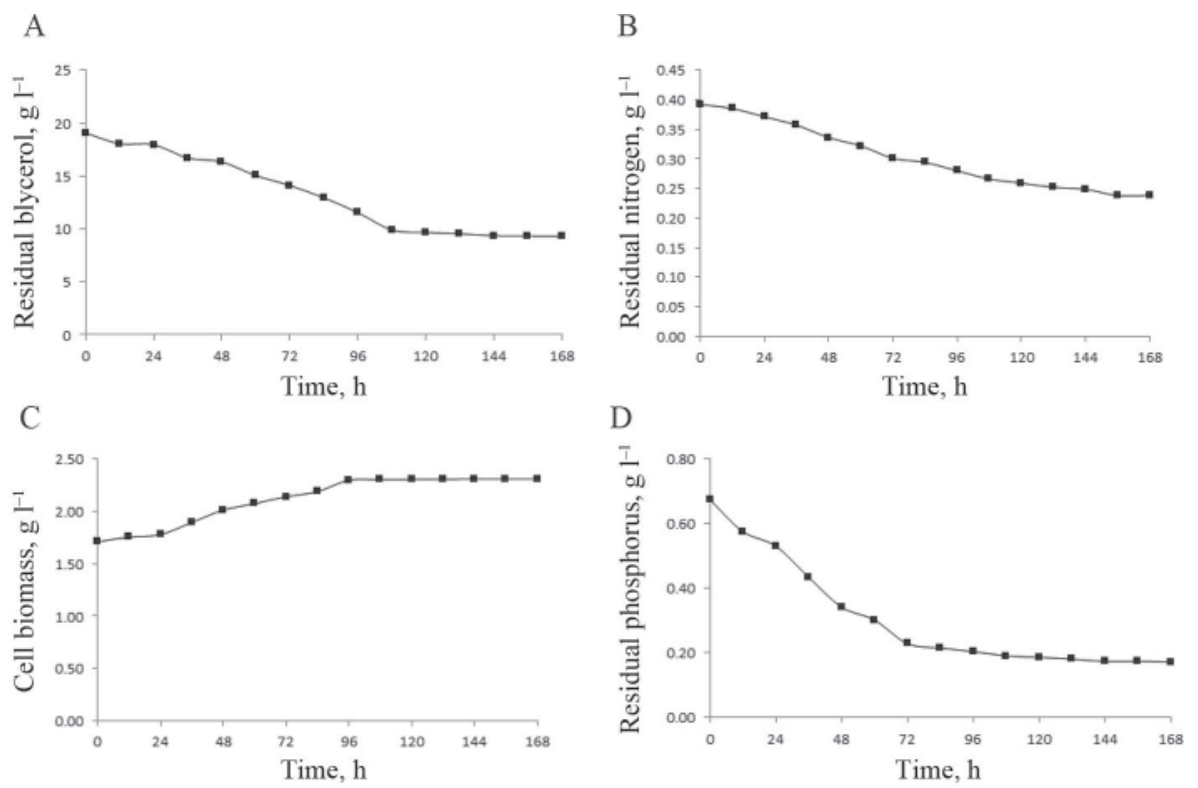

Fig. 1. Time course of residual glycerol content (A), residual nitrogen content (B), cell biomass (C), and residual phosphates (D) during 7 days of $S$. hygroscopicus cultivation in 31 bioreactor.

Based on the data obtained (Fig. 1A), it can be observed that consumption of glycerol is more intense at the start of biosynthesis up to $108 \mathrm{~h}$. This indicates that Streptomyces hygroscopicus uses this nutrient during growth phase. Glycerol content was reduced to $9.29 \mathrm{~g} \mathrm{l}^{-1}$ by the end of the bioprocess, but the residual glycerol can be used as a binder of the final product to plants, which would significantly affect the economy of production (GRAHOVAC et al., 2014). Also, this is an indication that $S$. hygroscopicus uses glycerol obtained as a byproduct of biodiesel production very well (Ćrrić et al., 2012; DodD et al., 2018). On the other hand, nitrogen and phosphorus are required by microorganisms both for growth and multiplication, and very often for the production of desired metabolites. Certainly, phosphorus affects the control of the biosynthesis of a large number of secondary metabolites (MARTIN, 2004). Nitrogen (Fig. 1B) and phosphorus (Fig. 1D) consumption is most intense during the exponential phase, and their values at the end of the bioprocess are $0.238 \mathrm{~g} \mathrm{l}^{-1}$ and $0.171 \mathrm{~g} \mathrm{l}^{-1}$, respectively.

Results of biomass growth show that exponential phase lasts until the fourth day, when stationary phase of the bioprocess, in which the consumption of nutrients is significantly reduced, begins (Fig. 1C). It can be assumed that the applied conditions did not favour biomass production. Also, it can be concluded that consumption of glycerol, nitrogen, and phosphorus is connected to biomass formation. 


\subsection{Effect of cultivation time on the production of active agents}

Applied conditions were selected according to results from the scientific literature, showing that lower agitation speed and aeration rate of $1.5 \mathrm{vvm}$ represent optimal conditions for the production of desired metabolites using streptomycetes (TECHAPUN et al., 2003; YEN \& LI, 2014). As the most favourable form for metabolite production by streptomicetes is small pellets (ILIĆ et al., 2008), high agitation speed can destroy the desired pellet form, thus adversely affecting the productivity of streptomycetes. The effect of Rushton turbine on the morphology of streptomycetes depends on the applied mixing rate. Also, with increased aeration rate, stationary phase, in which the desired antagonist agents are produced, occurs earlier (GOTTSCHALK et al, 2003). The statistical analysis was performed to determine whether the duration of cultivation affected the production of antifungal metabolites effective against four isolates tested.

Table 1. Results of factorial analysis of variance: sources of variation of inhibition zone diameter during 7 days of cultivation

\begin{tabular}{lrcccc}
\hline Source of variation & SS & $\begin{array}{c}\text { Degree of } \\
\text { freedom }\end{array}$ & MS & F-value & P-value \\
\hline Time & 12658.2 & 14 & 904.2 & 1251.9 & 0.00 \\
Test fungi & 1602.2 & 3 & 534.1 & 739.5 & 0.00 \\
TimexFungi & 1543.2 & 42 & 36.7 & 50.9 & 0.00 \\
Error & 86.7 & 120 & 0.7 & & \\
\hline
\end{tabular}

As expected, cultivation time had the most significant effect on inhibition zone diameter. Also, statistically significant differences $(\mathrm{P}<0.05)$ in the inhibition zone diameter were observed between the fungal isolates. Table 1 shows that interaction between these two factors (cultivation time and test fungi) also significantly affected inhibition zone diameter.

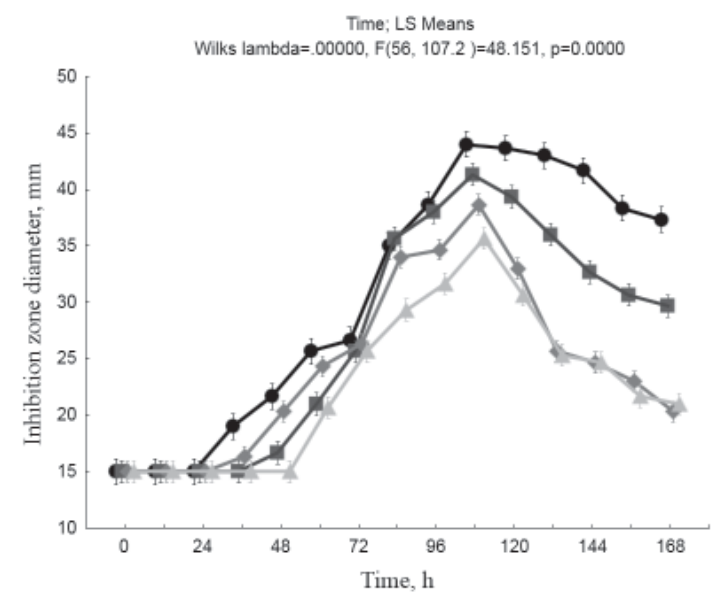

Fig. 2. Mean values of inhibition zone diameter ( $\mathrm{mm}$ ) of test phytopathogenic fungi caused by supernatant filtrate of $S$. hygroscopicus cultivation during 7 days of cultivation

프: 1 ; 프: KA10; 드: KA13; 프: KA12 
Figure 2 presents the mean values of inhibition zone diameter of two A. alternate and two $F$. avenaceum isolates caused by $S$. hygroscopicus supernatant during 7 days of cultivation on medium containing waste glycerol. Obtained results show that impressive antifungal activity was achieved between 4 and 5 days of $S$. hygroscopicus cultivation under defined conditions. According to TADIJAN and co-workers (2016), inhibition zone radius over $11 \mathrm{~mm}$ indicated that the applied antifungal agent is highly efficient. In our study, these inhibition zone diameters were formed after 60 hours of cultivation. This is important information, because it allows the bioprocess to be shortened, increasing its cost-effectiveness.

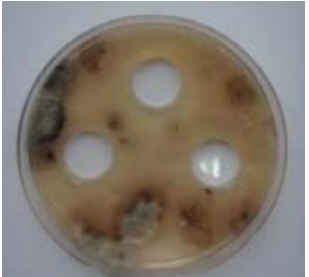

1a)

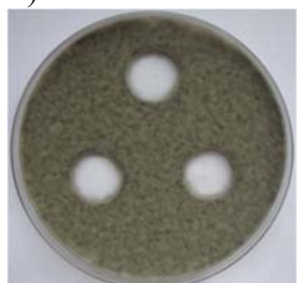

1b)

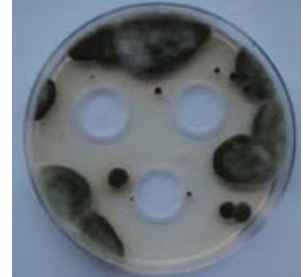

2a)

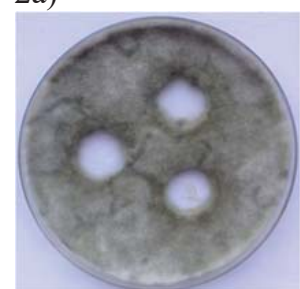

2b)

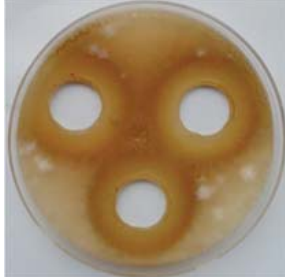

3a)

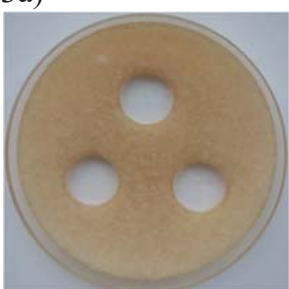

3b)

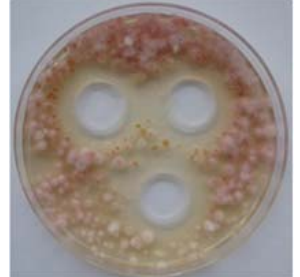

4a)

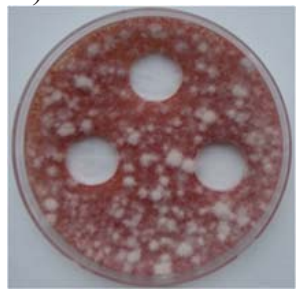

4b)

Fig. 3. Inhibition of mycelial growth using S. hygroscopicus supernatant obtained at $108 \mathrm{~h}$ of cultivation (a) and controls (b); (1) A. alternata T1Jg3; (2) A. alternate KA10; (3) F. avenaceum KA13; (4) F. avenaceum KA12

However, the largest inhibition zone diameters were formed at $108 \mathrm{~h}$ of cultivation for all phytopathogenic test isolates. Analysing results presented in Figure 2, it can be concluded that $A$. alternate $\mathrm{T} 1 \mathrm{Jg} 3$ is the most sensitive against produced bioagents (average inhibition zone $44 \mathrm{~mm})$, followed by A. alternata KA10 $(41.33 \mathrm{~mm})$. On the other hand, Fusarium isolates show less sensitivity to the produced bioagents, forming inhibition zone diameters of $38.67 \mathrm{~mm}$ for KA13 isolate and $35.67 \mathrm{~mm}$ for KA12 isolate. Since the tested isolates belong to different genera, their sensitivity to antifungal components could be different. Control of these types of phytopathogenic fungi is important, because they cause infections of apple fruit during storage, but also they are known as producers of mycotoxins harmful to human health (KonCZ et al., 2009; ElHARIRY et al., 2016).

\section{Conclusions}

The results obtained from these studies indicate the high potential of Streptomyces hygroscopicus to produce antifungal metabolites in medium containing waste glycerol in laboratory stirrer tank bioreactor at aeration rate of $1.5 \mathrm{vvm}$ and agitation of 100 r.p.m. Under these conditions, pellets responsible for the productivity of streptomycetes are formed. 
Results also showed that cultivation time has a statistically significant effect on production of antifungal agents by Streptomyces hygroscopicus. Anyhow, extending the bioprocess duration over 7 days would be considered economically unprofitable. Optimisation of the most important medium nutrients was not performed in this study, which is one of the reasons why not all nutrients of the medium were consumed at the end of the bioprocess. Also, use of different carbon sources as well as different mixing and aeration rates significantly affects the utilisation of the medium nutrients and the trend of production of antifungal metabolites using S. hygroscopicus. The in vitro study confirmed that the produced agents can successfully be used for biological control of stored apple fruit infected with phytopathogenic isolates $A$. alternate KA10 and T1Jg3 and $F$. avenaceum KA12 and KA13.

The authors gratefully acknowledge the support of the Ministry of Education, Science and Technological development of the Republic of Serbia within the framework of project 451-03-68 / 2020-14 / 200134.

\section{References}

Chatzifragkou, A., Makri, A., Belka, A., Bellou, S., Mavrou, M., ... \& Papanikolaoua, S. (2011): Biotechnological conversions of biodiesel derived waste glycerol by yeast and fungal species. Energy, 36, 1097-1108.

Ćirić, J.T., Ilić, S.B., Konstantinović, S., Veljković, V.B., Gojgić-Cvijović, G. \& Savić, D.S. (2012): Fermentacija glicerola pomoću bakterije Streptomyces hygroscopicus CH-7 (Fermentation of glycerol by Streptomyces hygroscopicus CH-7 bacterium). Savremene Tehnologie, 1(2), 20-25.

Dodd, A., Swanevelder, D., Zhou, N., Brady, D., Hallsworth, J.E. \& Rumbold, K. (2018): Streptomyces albulus yields $\varepsilon$-poly-1-lysine and other products from salt-contaminated glycerol waste. J. Ind. Microbiol. Biot., 45, 1083-1090.

Elhariry, H.M., Khiralla, G.M., Gherbawy, Y. \& AbD El Rahman, H. (2016): Natural occurrence of Alternaria toxins in pomegranate fruit and the influence of some technological processing on their levels in juice. Acta Alimentaria, 45(3), 380-389.

EPA (1979): EPA Manual 351.2. Determination of total Kjeldahl nitrogen by semi-automated colorimetry. 1979. Report No. EPA 60014-79-020.

Gales, M.E.J., Julian, E.C. \& Kroner, R.C. (1966): Method for quantitative determination of total phosphorus in water. J. Am. Water Works Ass., 58, 1363-1368.

Gottschalk, M.F.L., Nobrega, R. \& Bon, P.S.E. (2003): Effect of aeration on lignin peroxidase production by Streptomyces viridosporus T7A. Appl. Biochem. Biotech., 108, 799-807.

Grahovac, J., Grahovac, M., Dodić, J., Bajić, B. \& Balaž, J. (2014): Optimization of cultivation medium for enhanced production of antifungal metabolites by Streptomyces hygroscopicus. Crop Prot., 65, 143-152.

Ilić, S., Konstantinović, S., Savić, D., Veljković, V., Joković, N. \& Gojgić-Cvijović, G. (2008): The influence of modified media with carboxymethyl cellulose on morphology and antibiotic production by Streptomyces hygroscopicus. Biotechnol. Biotec. Eq., 22(1), 578-580.

JiAnG, M.Y., WANG, Z.R., Chen, K.W., KAN, J.Q., WANG, K.T., .. \& \& DU, M.Y. (2019): Inhibition of postharvest gray mould decay and induction of disease resistance by Pseudomonas fluorescens in grapes. Acta Alimentaria, 48, 288-296.

Koncz, Zs., NAÁr, Z., Kiss, A. \& SzÉCSI, Á. (2009): PCR-based assays for the identification of enniatin-producing Fusarium species associated to wheat. Acta Alimentaria, 38, 483-492.

Martin, J. (2004): Phosphate control of the biosynthesis of antibiotics and other secondary metabolites is mediated by the PhoR-PhoPsystem: An unfinished story. J. Bacteriol., 186(16), 5197-5201.

Meanwell, R.J.L. \& Shama, G. (2008): Production of streptomycin from chitin using Streptomyces griseus in bioreactors of different configuration. Bioresour. Technol., 99, 5634-5639.

Muthukumar, A., Sangeetha, G. \& Naveenkumar, R. (2016): Antimicrobial activity of essential oils against seed borne fungi of rice (Oryza sativa L.). J. Environ. Biol., 37, 1429-1436. 
Nunes, C. (2012): Biological control of postharvest diseases of fruit. Eur. J. Plant Pathol., 133, 181-196.

Ondul, E. \& DizGe, N. (2014): Glycerol: A major by-product in the biodiesel manufacturing process. J. Inst. Nat. Appl. Sci., 19 (1-2), 75-79.

Roume, H., Arends, J.B.A., Ameril, C.P., Patil, S.A. \& Rabaey, K. (2016): Enhanced production recovery from glycerol fermentation into 3-carbon compounds in a bioelectrochemical system combined with in situ extraction. Front. Bioeng. Biotech., 4, 73.

Sharma, P., Choudhary, B., Nagpure, A. \& Gupta, R.K. (2016): Antifungal potential of actinomicete isolate Streptomyces exfoliates MT9 against wood-rotting fungi. J. Environ. Biol., 37, 1231-1237.

Tadijan, I., Grahovac, J., Dodić, J., Grahovac, M. \& Dodić, S. (2016): Effect of cultivation time on production of antifungal metabolite(s) by Streptomyces hygroscopicus in laboratory-scale bioreactor. J. Phytopathol., 164, 310-317.

Techapun, C., Poosaran, N., Watanabe, M. \& Sasaki, K. (2003): Optimization of aeration and agitation rates to improve cellulase-free xylanase production by thermotolerant Streptomyces sp. Ab 106 and repeated fed-batch cultivation using agricultural waste. J. Biosci. Bioeng., 95(3), 298-301.

YEN, H.W. \& LI, Y.L. (2014): The effects of viscosity and aeration rate on rapamycin production in an airlift bioreactor by using Streptomyces hygroscopicus. J. Taiwan Inst. Chem. E., 45, 1149-1153.

Open Access statement. This is an open-access article distributed under the terms of the Creative Commons Attribution-NonCommercial 4.0 International License (https://creativecommons.org/licenses/by-nc/4.0/), which permits unrestricted use, distribution, and reproduction in any medium for non-commercial purposes, provided the original author and source are credited, a link to the CC License is provided, and changes - if any - are indicated. 